\title{
Da Revolução Cubana à Era Obama: das tensões à normalização
}

\section{From the Cuban Revolution to the Obama Era: from strains to normalization}

Alfredo Juan Guevara Martinez

Resumo: Desde a Revolução de 1959, as relações dos Estados Unidos com Cuba entraram em uma era de antagonismo e tensões políticas. Após quase meio século de uma proximidade íntima, os dois países passaram a ser inimigos em pleno contexto de Guerra Fria. O resultado disso foi que os Estados Unidos se engajaram em uma estratégia austera de política exterior com Cuba, cortando relações diplomáticas e impondo um embargo comercial que viria a se perpetuar por meio século. Mesmo com o fim do conflito bipolar, as relações antagônicas entre os dois países se mantiveram inalteradas e Cuba permaneceu um país em isolamento graças ao embargo comercial estadunidense. Foi somente em 2014 que a administração Obama apostou em uma estratégia diferente, quebrando um paradigma político de décadas e promovendo uma reaproximação com Cuba. Ainda assim, o processo de normalização nunca foi completo e evidenciou como a estratégia de política externa dos Estados Unidos para Cuba depende de diferentes atores domésticos e seus distintos interesses. Para compreender esse fenômeno é preciso entender como se formou a estratégia antiga, por que ela se perpetuou e quais foram as condições que levaram a que fosse possível sua quebra. Este artigo traz um estudo histórico dos principais eventos entre Cuba e Estados Unidos que ocorreram a partir da Revolução, buscando melhor explicar a formação e a mudança da estratégia de política externa estadunidense para Cuba, passando por eventos como a invasão da Baía dos Porcos, a Crise dos Mísseis, as diversas crises migratórias até o processo de normalização e ruptura da antiga estratégia promovido pelo governo Obama.

Palavras-chave: Cuba; Estados Unidos; Normalização

(cc) EY Direito autoral e licença de uso: Este artigo está licenciado sob uma Licença Creative Commons. Com essa licença você pode compartilhar, adaptar, para qualquer fim, desde que atribua a autoria da obra, forneça um link para a licença, e indicar se foram feitas alterações. 


\begin{abstract}
Since the Cuban Revolution in 1959, the relations between the United States with Cuba have entered an era of antagonism and political tensions. After more than half a century of close intimacy, both countries come to be enemies inside the context of the Cold War. As a result, the United States engaged in an austere strategy of foreign policy towards Cuba, ceasing diplomatic relations and imposing a commercial embargo that would come to perpetuates itself for more than fifty years. Even with the end of the bipolar conflict the antagonist relations between the countries remained unchanged, and Cuba remained in isolation thanks to the American embargo. It was only in 2014 that the Obama administration betted on a different strategy, breaking with decades old political paradigm and promoting a rapprochement with Cuba. Still, the process of normalization was never fully complete, and evidenced how the strategy of the United States foreign policy towards Cuba depends of different domestic actors and their diverse interests. To understand this phenomenon, it's needed to comprehend how the old strategy was formed, why was it perpetuated and which were the conditions that led to be possible to break it. This article brings a historical study of the main events that happened between Cuba and the United States since the Revolution, seeking to better explain the formation and changes of the American foreign policy strategy towards Cuba, going through events like the invasion of the Bay of Pigs, the Missile Crisis, the diverse migration crisis, up to the normalization process and the rupture of the old strategy promoted by the Obama government.
\end{abstract}

Keywords: Cuba; United States; Normalization

\title{
Introdução
}

A história contemporânea das relações entre os Estados Unidos e Cuba é marcada por mais de meio século de tensões. O início do governo da Revolução cubana veio acompanhado de uma longa trajetória de inimizades iniciadas no contexto da Guerra Fria, que se estendeu até dezembro de 2014, quando os governos de Barack Obama e Raúl Castro anunciaram um reatamento das relações diplomáticas e a intenção de ir rumo a uma normalização completa. Desde o século XIX houve vários momentos da história nos quais foi cogitado, tanto em Cuba como nos Estados Unidos, a anexação da ilha (nessa época, colônia espanhola) ao território estadunidense Apesar da anexação nunca ter ocorrido, Cuba foi historicamente vista pela política norte-americana como um satélite natural, que mesmo não estando sob seu controle direto, deveria estar sob sua influência e hegemonia. Durante essa época, os Estados Unidos não apenas interviram na guerra de independência do país vizinho, assumindo temporariamente seu governo após a derrota dos espanhóis, como também agregaram à constituição da recém-nascida República de Cuba a Emenda Platt. 
Tal emenda serviu como direito constitucional de intervenção e ingerência estadunidense durante toda a primeira metade do século XX, garantindo que seus interesses estivessem assegurados em Cuba (HOLDEN; ZOLOV 2000; SCHOULTZ, 2000; GRANDIN, 2007; PREVOST; 2015)².

A Revolução cubana não apenas rompeu com esse paradigma de uma Cuba satélite dos Estados Unidos, como também ocorreu no meio do conflito bipolar do país vizinho com a União Soviética, em uma época em que reformas sociais e agrárias eram vistas como claros sinais de inclinação comunista. Passados mais de cinquenta anos desde a Revolução, o contexto do mundo mudou, mas durante duas décadas do pós-guerra fria, as tensões entre Cuba e os Estados Unidos permaneciam aparentemente inalteradas. Assim como é corriqueira a descrição de Cuba como um país parado no tempo, graças aos automóveis antigos e infraestrutura clássica da primeira metade do século $\mathrm{XX}$, o mesmo podia ser pensado para suas relações com os Estados Unidos. O fim da União Soviética, e, portanto, da Guerra Fria, isolou a Ilha, porém o regime de Fidel Castro não se desfez e tampouco o clima de antagonismo com o governo estadunidense.

Durante a década de 1990, a política exterior dos Estados Unidos se manteve austera com Cuba, com a expectativa de que o governo de Fidel Castro entrasse em colapso sozinho, frente ao isolamento total graça ao embargo estadunidense. Não por acaso, nessa mesma época, a política do embargo se transformou em Lei. Novamente, a década de 1990 passou e o governo da Revolução se manteve, ocorrendo o mesmo na década seguinte. Contudo, já em 2008, algumas sutis mudanças começaram a aparecer em Cuba com o afastamento de Fidel Castro das funções de governo do país e a consequente posse de seu irmão, Raúl Castro. Simultaneamente, nos Estados Unidos, assumia o governo o presidente democrata Barack Obama, que ao longo de seus dois mandatos buscou trilhar um caminho diferente nas relações com Cuba.

O paradigma de relações tensas entre os dois países durou por mais de 50 anos sem dar sinais óbvios de que mudaria. Por essa razão, a aproximação reiniciada em 2014 pela gestão Obama com o governo de Raúl Castro é uma ruptura com uma tradição de política externa dos Estados Unidos para Cuba na história moderna. Vale apontar que a inciativa de normalização promovida por Obama foi parcial, visto que com o passar do tempo as políticas austeras de Cuba foram se enraizando no complexo sistema de produção de política externa dos Estados Unidos. Por meio do Poder Executivo Obama fez, teoricamente, tudo o que estava ao seu alcance para mudar a estratégia dos Estados Unidos em relação a Cuba, mas políticas importantes, como o embargo, dependem da aprovação de outros atores, do Congresso, e, portanto, de seus membros.

Apesar da ruptura da normalização, o processo não foi completo, devido à falta de consenso que se evidenciou entre a administração de Obama e os políticos e grupos interessados em manter uma política austera para Cuba. Ainda 
assim, a estratégia de Obama deu passos importantes para a solidificação de uma nova estratégia que não seja facilmente revertida por uma administração futura. O fechamento das embaixadas se deu sob um contexto conturbado, não bastasse a Guerra Fria, a Revolução Cubana levou os Estados Unidos a reagirem, financiando a frustrada invasão da Baía dos Porcos. Por mais que a austeridade política seja, desde então, uma tradição da política exterior dos Estados Unidos para Cuba, dificilmente um momento tão conturbado quanto o da época do fechamento das embaixadas voltará a se repetir. Assim, a reabertura das embaixadas é um passo sólido para pelo menos reestabelecer relações minimamente diplomáticas com Cuba.

Este artigo é um esforço de trazer um histórico da evolução da política externa dos Estados Unidos para Cuba, a partir do fechamento das embaixadas até a normalização iniciada pela gestão Obama. Trata-se de um estudo complementar à dissertação "O Processo Decisório do Cuban Adjustment Act: Variações de contexto e manutenção da lei (1966 a 2014)"’3, de nossa autoria, cujo capítulo 2 faz um resumo cronológico das relações migratórias entre Cuba e Estados Unidos. A descrição histórica abordada neste artigo expande o tema para as relações entre os dois países em um escopo mais geral de política externa e tem como intuito ajudar a compreender quais atores foram se mobilizando ao longo da história para influenciar e moldar de alguma forma a construção da estratégia política estadunidense para Cuba. Os fenômenos que serão analisados são os eventos de maior impacto internacional que fizeram parte da evolução e solidificação das tensões bilaterais, com foco maior nas ações e respostas dos Estados Unidos. Portanto, o recorte temporal vai desde a Revolução Cubana e o fechamento das embaixadas até o processo de normalização iniciado em 2014, bem como as últimas medidas da nova estratégia adotada por Obama nos últimos dias de sua administração em 2017.

\section{A Revolução Cubana}

Para começar a compreender a trajetória de inimizades entre Cuba e Estados Unidos dos últimos anos, é preciso se aprofundar um pouco no que foi a Revolução cubana e no processo que levou ao rompimento diplomático entre os países. Como já foi dito, a influência direta dos Estados Unidos na Cuba préRevolução data da própria independência da ilha. Ao entrar na Guerra Hispano Americana, os Estados Unidos acabaram terminando um conflito armado que já durava anos entre o exército independentista cubano e o exército espanhol. A entrada do robusto exército americano levou ao fato de que a primeira bandeira hasteada em uma Cuba independente fosse a estadunidense.

De 1898 a 1902 a ilha esteve sobre governo militar provisório dos Estados Unidos e em 1902, com a aprovação da emenda Platt na recémnascida Constituição de Cuba, o governo estadunidense gozava de liberdade para intervir e tutelar a ilha sempre que considerasse necessário. Durante os 
primeiros cinquenta anos da República de Cuba, os Estados Unidos puderam intervir livremente em suas diretrizes políticas, acessar sua economia e manter condições benéficas para seus interesses comerciais com a ilha. $\mathrm{O}$ embaixador dos Estados Unidos em Cuba era visto como uma figura que detinha até mais poder do que o Presidente cubano (SCHOULTZ, 2000; SUCHLIKI, 2002; BOSCH, 2009, PREVOST, 2015) 4 .

Contudo, a intervenção estadunidense direta no governo de Cuba passou a ser uma ferramenta menos utilizada depois da década de 1930. Com a Grande Depressão, seguida da Segunda Guerra Mundial, os Estados Unidos passaram a deixar que Cuba percorresse um caminho mais autônomo. É possível considerar que após 30 anos de laços comerciais intensos, que foram precedidos por quase um século de compra massiva de açúcar, a economia cubana já estivesse suficientemente dependente da economia dos Estados Unidos para que este deixasse a ingerência governamental em segundo plano.

Foi nesse contexto que o militar cubano Fulgencio Batista foi eleito democraticamente para a presidência de Cuba em 1940, cumprindo seu mandato de 4 anos e retornando ao poder em 1952, por meio de um golpe militar. O segundo governo de Batista foi marcado por um regime policial opressor a todo e qualquer tipo de oposição, instaurando uma ditadura violenta na ilha de Cuba. Aos poucos o governo dos Estados Unidos foi se distanciando de Batista e observando que tipo de movimento interno de transformação ocorreria em Cuba (PREVOST, 2015).

Assim, a Revolução cubana surge como um levante de guerrilha com a intenção de destituir Batista do Poder. É importante ressaltar que em Cuba houve diversos movimentos de insurgência internos, o próprio Fidel Castro liderou um assalto ao quartel Moncada em 26 de julho de 1953, sendo derrotado pelas tropas de Batista, preso e posteriormente exilado no México (SUCHLIKI, 2002; BOSCH, 2009). Durante o exílio de Castro, os Estados Unidos assistiram insurgentes se levantarem e serem massacrados pelo governo de Batista, como o Assalto do Diretório Estudantil ao Palácio do Governo em 1957.

Diferente dos movimentos revolucionários urbanos, o M-26, nome que se deu ao segundo levante de Fidel Castro, o enfrentamento ao governo se deu através de táticas de guerrilha na parte oriental, rural e montanhosa de Cuba, em 1956. Combatendo as forças de Batista fora de seu território habitual, a Revolução de Castro ganhou destaque internacional através de imprensa americana. Herbert L. Matthews, repórter do New York Times, foi levado por guerrilheiros até o acampamento secreto de Fidel Castro na Sierra Maestra e fez um artigo exaltando o sucesso da guerrilha. O artigo serviu de mecanismo de propaganda e legitimação para o movimento Revolucionário, que até então não tinha uma ideologia clara (HOLDEN; ZOLOV, 2000). Esse clima de incertezas serviu para que não só os Estados Unidos se afastassem 
do governo de Batista, mas também para que houvesse atores estadunidenses com uma visão positiva do grupo de revolucionário liderado por Castro.

Quando no dia primeiro de janeiro de 1959 a Revolução Cubana chegou ao Poder, o Executivo americano ainda tinha dúvidas quanto à orientação da nova liderança na Ilha. Che Guevara e Raúl Castro tinham proximidade com ideais marxistas e comunistas, mas o principal líder do movimento revolucionário, Fidel Castro, ainda era uma incógnita quanto ao seu posicionamento ideológico. Logo nos primeiros meses de governo, Fidel Castro foi convidado aos Estados Unidos para uma visita diplomática. Uma das intenções dessa visita era avaliar se o novo governo cubano era um potencial aliado, ou um potencial problema. Na época Eisenhower não teve interesse em se encontrar com Castro pessoalmente e enviou seu vicePresidente, Richard Nixon, para avaliar a inclinação do comandante cubano ao comunismo.

Nessa época, apesar de muito recente, o governo revolucionário vinha com algumas promessas que podiam ser vistas como mais inclinadas ao socialismo, como reforma agrária e as primeiras apropriações de propriedades privadas. Da parte dos cubanos, a cúpula de revolucionários que visitou os Estados Unidos era jovem, vinha de uma vitória árdua e tinha como característica clara o nacionalismo e a proteção da autonomia que eles haviam lutado para conseguir. Apesar de Fidel Castro ter insistentemente reiterado que não era comunista durante sua visita, para Leogrande e Kornbluh $(2015)^{5}$ a desconfiança estadunidense, combinada com a falta de experiência diplomática da delegação cubana e o próprio receio de perder sua autonomia, culminaram em um não entendimento entre as partes e o primeiro passo rumo a quebra de relações entre os dois países.

Em época de macarthismo e doutrina de contenção do comunismo, a avaliação do vice-Presidente Nixon foi a de uma inclinação ao comunismo, o que levou a gestão de Eisenhower a posteriormente começar os preparativos para a famosa invasão da Baía dos Porcos em 1961. Nos meses que se seguiram à visita de Castro aos Estados Unidos, o confisco de propriedades privadas por parte do Estado cubano aumentara, incluindo propriedades estadunidenses, o que levou a uma quebra definitiva entre o novo governo revolucionário e o do país vizinho.

\section{O Começo do Embargo}

A resposta à nacionalização de empresas e confiscos de propriedades privadas estadunidenses em Cuba culminou em uma retaliação do governo de Eisenhower por meio da redução da cota de importação de açúcar cubano, o principal motor econômico da Ilha. Para conseguir alavancar sua economia e dar continuidade às reformas e transformações que vinha fazendo, Fidel Castro encontrou na União Soviética a solução para desafogar o excedente 
de açúcar que seria destinado aos Estados Unidos. O país líder do bloco socialista, por sua parte, encontrou em uma Cuba que cada vez mais se distanciava dos Estados Unidos terreno fértil para expandir o alcance de seu bloco. Essa parceria entre Cuba e a União Soviética só agravou a visão negativa que o governo estadunidense tinha da Revolução Cubana. Não somente um país vizinho se tornava comunista, como o mesmo caia nas graças de seu pior inimigo (PREVOST, 2015 MORRONE, 2008; KIRK, $2009)^{6}$.

Como consequência da crescente aproximação entre Cuba e a União Soviética, o governo de Eisenhower continuou a limitar a cota de compra de açúcar da Ilha e impôs um embargo parcial do comércio com Cuba ainda em 1960. Esse foi o início de uma série de sanções de econômicas que iriam se agravar com o passar dos anos, até um embargo total ser imposto para todo comércio com Cuba em forma de Lei Federal nos Estados Unidos. O governo cubano viria a chamar o embargo de bloqueio econômico, sendo este um tema central nas relações entre Cuba e os Estados Unidos até a atualidade.

\section{O Rompimento de Relações Diplomáticas}

Já no começo de 1961 os discursos antagonistas entre Cuba e os Estados Unidos chegavam a um ponto alto, com o governo estadunidense apontando o vizinho como uma nova ameaça comunista, e, por sua vez, sendo acusado de ter uma política exterior imperialista. Na percepção do governo dos Estados Unidos, o regime de Castro tinha seus dias contados, visto que a Revolução era recente e se esperava que as pressões econômicas tirassem as ferramentas do governo cubano de viabilizar seu projeto de poder. No entanto, o apoio econômico soviético ajudou a manter estável o governo de Castro, que internamente arquitetou uma série de reformas domésticas para consolidar sua posição de liderança. Ciente do interesse dos Estados Unidos de não aceitar o novo governo de Cuba, o país adentrou cada vez mais no bloco socialista. Assim, em 3 de janeiro de 1961, Eisenhower fechou a embaixada dos Estados Unidos em Cuba. A diplomacia tradicional entre os dois países permaneceu inexistente por mais de 50 anos e as relações formais, a partir desse momento, eram realizadas pelas oficinas de interesses.

\section{A Invasão da Baía dos Porcos}

O governo de Eisenhower encerrou sua administração com um plano de ação definido para Cuba: apoiar uma invasão armada de cubanos contrários a Castro. Apesar de não enviar tropas próprias, a CIA supervisionaria o treinamento realizado na Guatemala, bem como a estratégia de invasão. A ideia era derrubar o governo de Castro ainda em sua fase inicial e evitar que a Ilha se tornasse um território suscetível à influência soviética (LEOGRANDE, KORNBLUH, 2015). 
Nas eleições de 1960, Richard Nixon - que participou do governo de Eisenhower na formulação da estratégia para Cuba - acabou perdendo as eleições, fazendo com que o plano de invasão "caísse no colo" do Presidente eleito Kennedy, como uma operação já em caminho herdada da administração anterior. O novo governo dos Estados Unidos optou por levar adiante a invasão, mas efetuou algumas mudanças táticas nas estratégias de apoio aos cubanos que levariam a cabo a ação.

Assim, em 17 de abril 1961 a chamada "Brigada de Assalto 2056", nome dado ao grupo de cubanos que participaram da ação, desembarcou na Baía dos Porcos em Cuba, dando início a um confronto militar que durou dois dias, terminado com a derrota dos invasores. O governo de Fidel Castro tomou como prisioneiros de guerra os sobreviventes, forçando o governo dos Estados Unidos a negociar sua liberdade (SUCHLIKI, 2002; BOSCH 2009).

Defensores da invasão e os próprios cubano-americanos que participaram da operação atribuem sua derrota militar à falta de apoio de Kennedy, inclusive apontando que o então Presidente teria prometido um reforço aéreo que nunca chegou. Considerando que as relações de Cuba se estreitavam cada vez mais com a União Soviética, percebe-se que as escolhas do governo dos Estados Unidos acerca da invasão da Baía dos Porcos foram cautelosas no sentido de evitar que essa ação pudesse agitar irreversivelmente a Guerra Fria. Por conseguinte, a decisão de invadir a ilha com tropas que não fossem oficialmente dos Estados Unidos, além de não dar apoio militar direto, eram sinais de que Cuba já se transformava em um perigoso palco de tensões para o conflito bipolar. Ironicamente, as consequências da Invasão da Baía dos Porcos terminaram por acelerar a confirmação dessa transformação.

\section{A Crise dos Mísseis}

A vitória sobre os invasores da Baía dos Porcos ajudou a assegurar ainda mais a posição de Fidel Castro como liderança em Cuba. Além do mais, a invasão legitimou o discurso de que o governo dos Estados Unidos era imperialista, reafirmando seu papel como inimigo externo da Revolução Cubana. Porém, pragmaticamente, o governo cubano encontrava-se em uma situação de vulnerabilidade, pois se tornaram mais que evidentes as intenções do país vizinho de desfazer o regime da ilha.

Do lado dos Estados Unidos, por sua vez, a derrota teve consequências desastrosas. Não apenas a invasão fracassou em seu objetivo, como deu mais ferramentas retóricas para Fidel Castro solidificar seu poder em Cuba. Ademais, o governo cubano tirou proveito dos prisioneiros obtidos na invasão e coletou um generoso valor de resgate para a libertação dos cubanos da "Brigada 2056". Entretanto, talvez a consequência mais grave para os Estados Unidos foi a aceleração do processo de alinhamento de Cuba com o bloco soviético. 
A partir da invasão de 1961, Cuba começou a estreitar laços militares com a União Soviética, uma vez que não apenas os Estados Unidos deixaram de ser uma fonte de comércio, como também se tornaram uma ameaça real à Revolução Cubana. Como resultado, em sigilo, a União Soviética mandou tropas para Cuba e instalou um arsenal nuclear na ilha. Com essa nova conjuntura, uma nova tentativa de invasão estadunidense significaria também um confrontamento militar direto com a União Soviética (KIRK, 2009).

Em resposta à existência de arsenal nuclear estadunidense na Turquia e na Europa, a União Soviética instalou mísseis em Cuba. Quando os Estados Unidos confirmaram a existência de mísseis nucleares soviéticos em Cuba, o mundo passou pela crise nuclear mais próxima de se tornar uma hecatombe global, sendo o pico da crise em outubro de 1962. Para o governo cubano, apesar de o evento ter deixado o mundo a um passo da guerra nuclear, ele serviu como proteção para intervenções militares dos Estados Unidos na Ilha. Existem diversos trabalhos e estudos canônicos que narram e analisam em profundidade os aspectos político sociais da Crise dos Mísseis de Cuba, como o livro de Alisson e Zelikow (1999) "The Essence of Decision: Explaining the Cuban Missile Crisis"'.

Na prática, a Crise dos Mísseis foi resolvida por meio de negociações diplomáticas entre os Estados Unidos e a União Soviética, nas quais os mísseis seriam retirados da Ilha em troca da retirada dos mísseis na Turquia. O governo cubano foi colocado em segundo plano na resolução do conflito, enquanto Fidel Castro se manifestava publicamente contra a retirada dos mísseis soviéticos. Porém, a solução da crise trouxe consequências históricas para as relações futuras entre Cuba e Estados Unidos, uma vez que o governo de Kennedy se comprometeu a não invadir ou intervir militarmente no vizinho (MORRONE, 2008; GOTT, 2006; DÍAZ, 2000) ${ }^{8}$.

Apesar da Crise dos Mísseis ter ocorrido apenas dois anos após a chegada do governo da Revolução em Cuba, as tensões desencadeadas por ela serviram para moldar o tom das relações com os Estados Unidos pelas décadas seguintes. Um fato que contribuiu para isso, mas pouco estudado, foram as intenções não concretizadas do governo Kennedy de averiguar a possibilidade de um diálogo com Cuba. Como foi constatado anteriormente, a administração de Kennedy acabou herdando a estratégia de antagonismo ofensivo contra Cuba dos últimos momentos do governo Eisenhower, não somente a invasão da Baía dos Porcos era um plano que já estava encaminhado, como o fechamento das embaixadas e corte de relações diplomáticas com Cuba foi feito na véspera da posse do novo Presidente, dificultando qualquer chance de diálogo. Contudo, uma vez solucionada a Crise dos Mísseis, o comprometimento com a não intervenção poderia ter sido um caminho para o reestabelecimento de diálogos com a Ilha, mas o presidente Kennedy foi assassinado antes que qualquer iniciativa concreta pudesse ser tomada. 


\section{A Imigração e o Cuban Adjustment Act}

O presidente Lyndon Johnson, que sucedeu Kennedy após sua morte, acabou não adotando nenhuma estratégia distinta em relação à política externa para Cuba, mantendo o que viria a se tornar um paradigma de estrangulamento silencioso e isolamento da Ilha. Como naquele contexto a Revolução Cubana ainda era recente, no imaginário dos políticos estadunidenses, a manutenção do isolamento da Ilha seria uma forma eficaz de esperar o governo cubano colapsar. No entanto, o tempo mostrou que a realidade viria a ser diferente.

Assim, em 1966 foi aprovado no Congresso dos Estados Unidos o Cuban Adjustment Act. Neste momento já se encontrava no país uma quantidade expressiva de cubanos dissidentes da Revolução de 1959 (GOTT, 2006; MORRONE, 2008). Cuba, então, representava o inimigo comunista na porta dos Estados Unidos, graças à sua proximidade geográfica e à incapacidade da potência capitalista em derrubar efetivamente o recém implantado governo de Castro. O resultado dessa primeira onda migratória de cubanos, que deixavam a ilha por motivos de cerne político e ideológico, junto ao início das relações de antagonismo entre Cuba e Estados Unidos, levou à criação dessa política especial para ajustar o status migratório dos cubanos.

A Lei acolhia os cubanos dissidentes, visto que estes eram contra o novo inimigo dos Estados Unidos, e, portanto, compartilhavam com o governo do país o interesse "anticastrista". A criação do Cuban Adjustment Act serviu como ferramenta para os Estados Unidos sanarem um problema doméstico burocrático de regularização de uma quantidade expressiva de imigrantes e, ao mesmo tempo, utilizar a Lei como ferramenta política internacional para desmoralizar o governo Castro, já que juntamente com o embargo econômico, era possível pressionar a economia cubana e, simultaneamente, oferecer uma saída aos cubanos insatisfeitos. Na prática, a Lei permitia o ajuste para um status migratório permanente e legal de qualquer cubano que houvesse passado 1 ano e 1 dia nos Estados Unidos, independentemente de sua entrada ter sido legal ou não.

Desde sua criação, o Cuban Adjustment Act não sofreu nenhuma alteração significativa, na verdade, apenas foram incrementados benefícios à Lei especial para cubanos. Essa política sempre foi considerada tendenciosa e imperialista pelo governo de Cuba, sendo utilizada pelos Estados Unidos como ferramenta para estimular a emigração cubana como forma calculada de desacreditar a Revolução e o sistema comunista.

É importante considerar que, após a invasão da Baía dos Porcos e o alinhamento definitivo do vizinho ao bloco soviético, os Estados Unidos mudaram a percepção acerca da Revolução Cubana e seu novo regime, e, em conjunto com as primeiras medidas de embargo econômico contra a ilha, foram suspendidos os voos para Cuba. Este fenômeno foi o estopim do surto de imigrações ilegais, que entre 1962 e 1965 levou a mais de 30.000 cubanos 
emigraram dessa forma para os Estados Unidos. Frente a essa situação, de outubro de 1965 até novembro do mesmo ano, foi autorizada pelo governo de Castro a entrada de embarcações no porto de Camarioca, para que os cubanoamericanos pudessem buscar familiares na ilha. Esses eventos levaram à primeira tentativa dos dois países de regularizar a questão migratória.

Desta forma, no ano anterior à aprovação do Cuban Adjustment Act, com o intuito de facilitar o fluxo dos dissidentes cubanos da diáspora pós-revolução de 1959, os governos dos Estados Unidos e Cuba acordaram uma abertura de ponte aérea que permitisse o processo de saída por vias legais dos emigrantes cubanos (DÍAZ, 2000, p16-18). Essa foi a situação até 1973, quando a gestão do Presidente Nixon adotou uma postura política mais dura em relação ao regime cubano e suspendeu a ponte aérea entre os dois países. Assim, o fluxo de migrações legais cessou junto com a ponte aérea, aumentando o fluxo de migrações ilegais de cubanos para os Estados Unidos. Este fenômeno contribuiu para os eventos que ocasionaram a crise do porto de Mariel em 1980.

\section{Crise do Porto de Mariel}

Em abril de 1980, um grupo de cubanos entrou à força com um ônibus na embaixada do Peru, em Miramar, na Havana, matando um guarda cubano que trabalhava na frente do local. A embaixada concedeu o asilo político solicitado pelos cubanos e, como resposta, Fidel Castro ordenou a retirada da guarda policial da embaixada, o que permitiu que uma multidão de 10.000 cubanos entrasse no prédio e pedisse asilo político também (MORRONE, 2008; GOTT, 2006). O governo cubano ainda organizou um manifesto público de repúdio aos dissidentes sediados na embaixada peruana, considerando que estes não tinham a intenção de ir ao Peru, mas sim de conseguir passagem para os Estados Unidos.

Foi nesse contexto que Fidel Castro decidiu abrir as portas do Porto de Mariel, em Havana, para a entrada de embarcações que iam buscar mais cubanos desejosos por emigrar para os Estados Unidos, similarmente à abertura do porto de Camarioca, mas desta vez sem o objetivo específico da reunificação familiar, mas sim da limpeza de todos os dissidentes da Revolução Cubana. Durante 6 meses, centenas de embarcações oriundas da costa da Flórida entraram no Porto de Mariel para levar os cubanos que quisessem ir para o vizinho.

Durante esse período emigraram para os Estados Unidos cerca de

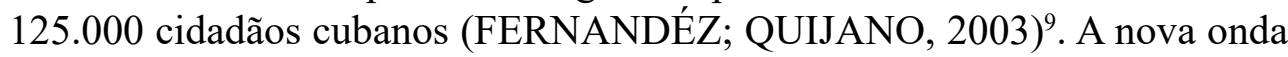
migratória, desta vez, mudava o perfil demográfico e social da comunidade cubano-americana, visto que uma grande parte desse contingente de imigrantes não possuía parentesco com nenhum cubano que já residisse nos Estados Unidos. Ademais, diferentemente da primeira diáspora migratória com maioria branca, neste episódio grande parte dos emigrados eram mestiços, negros e/ ou de segmentos mais pobres da sociedade cubana (DÍAZ, 2010; GOTT, 
2006). Somado a isso, entre os novos imigrantes havia um grande número de criminosos que eram detentos nas cadeias cubanas e foram liberados para participar do êxodo emigratório, chegando em grande quantidade ao território estadunidense. O resultado disso foi que na Crise de Mariel pelo menos 2.746 dos recém-chegados foram qualificados como inaceitáveis pelas autoridades dos Estados Unidos, sendo presos assim que chegaram no país (DÍAZ, 2000).

O êxodo do porto de Mariel resultou em um desastre político para o então presidente dos Estados Unidos, Jimmy Carter, pois a falta de medidas de segurança para a filtragem de imigrantes cubanos permitiu que o governo de Castro se utilizasse do episódio como ferramenta política para limpar o sistema penitenciário cubano e, ao mesmo tempo, atingir os Estados Unidos, a comunidade cubano-americana dissidente e o Cuban Adjustment Act. Ao se aproveitar da Lei migratória, o governo cubano utilizou a oportunidade para mandar milhares de ex-detentos e pacientes de sanatórios mentais cubanos, que, em tese, seriam aceitos no país sumariamente. Dessa forma, se modificava o panorama social positivo que, até então, caracterizava a comunidade cubana residente nos Estados Unidos. O próprio governante da ilha, Fidel Castro, declarou que havia dado a descarga nas latrinas de Cuba nos Estados Unidos, visto que o Cuban Adjustment Act criou condições para que isso fosse feito.

Sob a administração do governo republicano de Ronald Reagan, depois de quase 4 anos, o resultado do êxodo de Mariel foi que representantes de ambos os países se reuniram para debater uma possível normalização do problema migratório e, assim, Cuba e os Estados Unidos chegaram ao que foi chamado de Acordo de Normalização das Relações Migratórias de 1984 (DÍAZ, 2000; CHÁVEZ, 1996; MORRONE, 2008; GOBIERNO DE LA REPUBLICA DE CUBA, 2014) ${ }^{10}$.

\section{Radio Martí e Suspensão dos Acordos Migratórios}

Em setembro de 1985 o Congresso dos Estados Unidos aprovou a concretização da Rádio Martí. A mesma já operava desde maio daquele ano por iniciativa do presidente Reagan e sua função era transmitir um sinal de rádio que alcançasse a ilha de Cuba, com conteúdo e propaganda política e ideológica anti-castrista. A rádio era, entre outras coisas, parte da estratégia política do governo norte-americano de endurecimento da política externa para Cuba. Em contrapartida ao início das operações da Rádio Martí, o governo cubano suspendeu o cumprimento dos Acordos Migratórios assinados no ano anterior, considerando que a rádio violava o direito internacional, a soberania da ilha $\mathrm{e}$ era um ataque a Cuba (LAMRANI, 2003; GOBIERNO DE LA REPUBLICA DE CUBA, 2015) ${ }^{11}$.

No ano seguinte, delegações dos dois países se encontraram no México para tentar solucionar a questão, mas os resultados das negociações se mostraram infrutíferos. A delegação cubana chegou a sugerir a criação de uma transmissão 
de rádio de Cuba para os Estados Unidos, como resposta à Rádio Martí, mas a ideia não foi aceita pela outra parte e nem se concretizou. No mesmo ano, em resposta ao descumprimento dos Acordos de 1984, a administração de Reagan suspendeu a concessão de vistos legais para cubanos que tentassem obter o visto por meio de terceiros países a partir daquele ano, salvo exceções de perseguição política, parentes próximos de cidadãos americanos e/ou cubanos residentes legais nos Estados Unidos. Somente em 1987, os governos dos dois países conseguiram entrar convergit para revalidar o Acordo de Normalização das Relações Migratórias de 1984, mediante comprometimento para continuar negociando acerca das transmissões da Rádio Martí.

\section{A Lei Torricelli}

A dissolução da União Soviética e o término da Guerra Fria levou ao que Pecequilo (2005) chamou de organização de uma nova ordem mundial, com os Estados Unidos como centro principal de influência hegemônica ${ }^{12}$. O fim do bloco socialista culminou no isolamento econômico da ilha. Excluída política e economicamente, Cuba continuava sob as sanções comerciais praticadas pelos Estados Unidos desde 1962, o que afetava o intercâmbio de produtos com os demais países do bloco capitalista. E naquele momento, mais do que nunca, o embargo servia como ferramenta para sufocar o governo de Fidel Castro.

Foi nesse contexto de mudança de ordem global que o bloqueio virou questão central das relações bilaterais entre Cuba e os Estados Unidos. Em outubro de 1992, durante a campanha eleitoral para a presidência norteamericana, foi aprovado o Cuban Democracy Act no Congresso, ou LeiTorricelli (MORRONE, 2008). O propósito da Lei consistia no endurecimento das restrições comerciais do embargo, como forma de estimular a derrocada do regime de Castro e uma transição pacífica do país para um modelo de governo democrático.

A administração de Bush (pai) se manifestou contra o endurecimento do embargo devido ao caráter extraterritorial que o mesmo poderia representar, porém, ao se aproximar do período em que tentaria a reeleição, por motivos de pressão interna do partido, o presidente se posicionou favorável à criação da Lei, assim com seu rival, o então candidato Bill Clinton. Morrone (2008), sugere que o posicionamento tardio de Bush pode ter afetado negativamente sua imagem com os eleitores cubano-americanos mais conservadores, prejudicando, portanto, suas chances de vitória.

Na prática, a Lei Torricelli expandia as restrições de comercialização com Cuba para embarcações que tivessem passado recentemente na Ilha, afetando diretamente o comércio de outros países com os Estados Unidos, caso houvesse uma rota que incluísse Cuba. A Lei Torricelli servia como reforço do embargo, mas que ainda era uma política majoritariamente pertencente ao Poder Executivo. 


\section{O "Período Especial" e a Crise dos Balseiros}

Com Cuba isolada, os efeitos do embargo se agravaram, e a ilha entrou no que foi chamado "Período Especial". Uma série crise econômica e de escassez atingiu a sociedade cubana, cuja consequência foi o terceiro grande êxodo migratório cubano, a "Crise dos Balseiros" de 1994. A palavra Balseiros foi utilizada porque, diferentemente dos êxodos de Mariel e Camarioca, o governo cubano não havia autorizado a saída dos dissidentes, forçando os cubanos dissidentes a arriscassem suas vidas no mar, recorrendo a balsas improvisadas. Como consequência dessas saídas irregulares, se desconhece o número exato de vítimas fatais de naufrágios na tentativa de ir de Cuba aos Estados Unidos (FERNADEZ; QUIJANO, 2003; CARCANHOLO; NAKATAMI, 2002; DÍAZ, 2000).

A situação da crise dos balseiros levou a que, apenas no verão daquele ano, mais de 30.000 cubanos saíssem ilegalmente de Cuba. Como consequência, frente à possibilidade de que o desastre político do Porto de Mariel se repetisse, a administração Clinton instruiu sua guarda costeira a transportar os balseiros recolhidos em alto mar para a base militar de Guantánamo. Assim, ainda em setembro daquele ano haviam de 21.000 cubanos à espera de uma solução para a situação (GOTT, 2006). Frente a essa situação, o governo de Clinton optou por tentar conter o fluxo dos balseiros o quanto antes, fazendo com que Estados Unidos e Cuba reabrissem os canais de diálogo sobre o tema migratório (ROY, 2009; DÍAZ, 2010; MORRONE, 2008).

\section{A política Wet Feet/ Dry Feet}

Como parte do resultado dos novos diálogos migratórios, o governo de Clinton criou a política Wet Feet/Dry Fee (Pés Secos/Pés Molhados). O acordo se tratava de um comprometimento dos Estados Unidos de que todos os cubanos que sua Guarda Costeira recolhesse ainda no mar (Wet Feet) seriam levados de volta à Cuba. Em contrapartida, o governo de Cuba garantiria que não haveria represálias contra os dissidentes deportados. Contudo, os cubanos que chegassem ao território dos Estados Unidos (Dry Feet) não seriam deportados, abrindo a possibilidade para que pedissem refúgio e aplicassem ao ajuste migratório via Cuban Adjustment Act.

\section{A Lei Helms-Burton}

Como os acordos de 1995 e 1994 previam, os Estados Unidos, além de aumentar o patrulhamento costeiro para a aplicação da política dos Pés Secos/ Pés Molhados, também desencorajavam a interferência de cidadãos de seu país em atividades que dessem assistência à imigração cubana ilegal. Ainda assim, uma das organizações de cubano-americanos atuava ativamente na questão da migração ilegal, a Hermanos al Rescate (Irmãos ao Resgate), se dedicada a fazer voos com aeronaves particulares, sobre o trecho de mar entre Cuba e 
Estados Unidos, buscando localizar e prestar assistências a balseiros cubanos à deriva no mar

Em 1996, a organização foi mais além de seu propósito humanitário e passou a sobrevoar o espaço aéreo da ilha de Cuba, espalhando panfletos com propaganda anticastrista sobre o território. O governo de Castro expressou que qualquer embarcação ou aeronave que invadisse seu território sem autorização seria abatida e a responsabilidade seria daqueles que "estimulam, planejam, executam ou toleram esses atos de pirataria" (GRANMA, apud GOTT, 2006, p.337). Dessa forma, no começo de 1996, duas aviões do grupo Hermanos al Rescate foram abatidas ao entrar no espaço aéreo cubano. A ação foi interpretada pelo governo dos Estados Unidos como uma afronta por parte do governo Castro, servindo como combustível para acelerar o debate que já tramitava no Congresso estadunidense acerca do embargo comercial contra Cuba (DÍAZ, 2010; MORRONE, 2008).

Impulsionado pelo abatimento das aeronaves, no dia 15 de março de 1996 o Cuban Liberty and Democratic Solidary Act, ou Lei Helms-Burton (nome dos autores da lei) foi aprovado no congresso e sancionado por Bill Clinton, com uma ampla oposição da comunidade internacional, devido ao seu caráter extraterritorial. A Lei-Helms-Burton convertia o embargo comercial a Cuba em Lei Federal nos Estados Unidos (HOFFMANN, 1997; CARCANHOLO; NAKATAMI, 2002) $)^{13}$. Na prática, o ato representava a consolidação do embargo como irrevogável enquanto o regime de Castro se mantivesse no poder. A partir daquele momento, apenas o Congresso dos Estados Unidos poderia revogar o embargo econômico, desde que os procedimentos previstos na Lei HelmsBurton para uma redemocratização da ilha de Cuba não ocorressem, tirando a possibilidade do Poder Executivo de retirar o embargo comercial de forma unilateral (MORRONE, 2008; LAMRANI, 2003).erherHe

Desde a sua criação, a Lei Helms-Burton se tornou no símbolo do conflito entre os Estados Unidos e Cuba dentro do contexto mundial que veio depois da Guerra Fria. A conversão do embargo em Lei Federal, bem como a impossibilidade de ser anulada por ato Executivo, indica a percepção temporal que o governo estadunidense passa a ter sobre a resistência e a durabilidade do regime de Castro. Com a Lei Helms-Burton aprovada ficou evidente que o governo dos Estados Unidos passou a apostar suas fichas cada vez mais no estrangulamento comercial como estratégia política de longo prazo frente ao governo da Revolução Cubana.

\section{O Caso Elian Gonzales}

Em 1999 teve lugar o chamado caso de Elian Gonzales, uma criança cubana que foi resgatada em alto mar pela guarda-costeira estadunidense, sobrevivente de um naufrágio de balseiros cubanos que tentavam alcançar a costa da Flórida. Os demais 12 passageiros da balsa perderam as vidas na 
tentativa de chegar aos Estados Unidos, incluindo a mãe de Elian. A criança foi acolhida temporariamente pela família de seu tio, residente na Flórida. A partir deste ponto, o evento se transformou em palco para um episódio importante nas relações bilaterais entre Cuba e os Estados Unidos. O pai de Elian, que permaneceu na Ilha, exigiu que Elian fosse retornado à Cuba. O governo cubano pressionou a administração Clinton para que os acordos de 1995 fossem cumpridos e Elian voltasse para a Ilha. Em contrapartida, a comunidade cubano-americana, em geral, e a organização Cuban American National Foundation (CANF) se colocaram do lado da família que residia na Flórida, exigindo que o governo dos Estados Unidos não cedesse à pressão do regime cubano e permitisse que a criança permanecesse nos Estados Unidos. A conclusão do episódio foi que a administração de Clinton optou por cumprir os acordos migratórios e devolver Elian Gonzales para Cuba, descontentando fortemente a comunidade cubano-americana e a família da criança nos Estados Unidos (ALZUGARAY, 2004; DÍAZ, 2000) ${ }^{14}$.

$\mathrm{O}$ evento se torna importante para a história das tensões entre Cuba e Estados Unidos, pois desde a crise de Mariel a comunidade cubano-americana foi se tornando cada vez mais engajada na esfera política dos Estados Unidos, inclusive se candidatando a cargos Legislativos e tendo a representação de vários distritos da Flórida. Na aprovação da Lei Torricelli e da Lei HelmsBurton houve amplo apoio dos setores mais conservadores e organizados cubano-americanos. Especialmente no caso da Lei Torricelli, que foi discutida em época de campanha presidencial, ambos candidatos presidenciais procuraram se aproximar dos interesses dos cubano-americanos para assegurar votos na Flórida.

Com base na importância política dos cubano-americanos para o desenho eleitoral, muitas análises apontam que o episódio de Elian Gonzales acabou criando uma imagem negativa para o partido Democrata de Bill Clinton. Nas eleições para presidente dos Estados Unidos, no fim do ano de 2000, o candidato do partido Republicano, George W. Bush, foi vitorioso em uma disputa acirrada com Al Gore, que concorria pelo partido Democrata. A decisão final das eleições ocorreu no estado da Flórida, por uma diferença 537 votos populares, que acabaram por lhe conceder todos os 25 votos representantes do Colégio Eleitoral da Flórida, atingindo, assim, a maioria dos votos dos colégios eleitorais do país, necessária para sua eleição. Esses 537 votos, combinados com o sistema de colégio eleitoral indireto, fizeram com que, pela segunda vez na história dos Estados Unidos, um candidato vencesse as eleições sem obter a maioria dos votos populares. Com uma margem tão pequena de votos tendo feito a diferença no resultado final das eleições, é possível inferir que qualquer ação política que houvesse impactado positivamente ou negativamente nas preferências de alguns eleitores poderia ter sido decisiva para a eleição presidencial. Essa inferência ganha força quando se pensa no descontentamento 
dos cubano-americanos no caso Elian, somado ao fato de que se estima que na década de 1990 membros da comunidade cubano-americana contribuíram com cerca US\$754.000,000 em campanhas federais, sendo superados, apenas, pela comunidade judaica pró-Israel, considerado o Lobby étnico mais poderoso nos Estados Unidos (GUTIÉRREZ, 2002) ${ }^{15}$.

É amplo o consenso na literatura de que o episódio de Elian Gonzales pode ter contribuído para a vitória de Bush. Além disso, Marrawi e Mendes (2005) indicam que muitos cubano-americanos enxergavam na plataforma Bush uma política externa para Cuba mais bem definida, enquanto que o candidato Al Gore tinha, em sua campanha, mais foco em questões como meio-ambiente e a temática humanitária ${ }^{16}$. Dessa forma, as relações entre Cuba e os Estados Unidos sob o governo de George W. Bush já começavam, desde a campanha eleitoral, apresentando um caráter de mudança e de endurecimento, estando em grande parte alinhadas com as preferências dos grupos de interesse cubanoamericanos mais conservadores. Esse contexto viria a ficar mais bem delineado após os atentados terroristas de 11 de Setembro de 2001, que representaram uma profunda mudança no contexto do mundo.

\section{Período Bush e Congelamento das Relações}

$\mathrm{Na}$ questão da política direta para Cuba, durante o governo de Bush foi criada a Comission on Assistance to a Free Cuba, com o objetivo de formular estratégias que auxiliassem na formulação de um plano para uma eventual transição democrática na ilha sem a presença do regime de Castro. Bush declarou que a iniciativa era um esforço para promover os interesses do povo cubano, o fim da tirania e a liberdade dos cubanos. Entre suas estratégias estava o encorajamento de alocação de recursos para organizações que velassem pela proteção dos dissidentes do governo cubano e pelos direitos humanos. Entre essas organizações, o presidente destacava o apoio direto à rádio (e agora TV) Martí. Além disso, as medidas que ele promovia incluíam a limitação das remessas de dinheiro a Cuba e do turismo estadunidense na ilha, visto que esse influxo de capital na verdade seria revertido para o governo cubano, permitindo que este utilizasse essas atividades como forma de perpetuar seu controle (BUSH, 2002 apud MORRONE, 2008; AYERBE, 2004) ${ }^{17}$.

$\mathrm{O}$ endurecimento das relações exteriores com Cuba no período Bush e o foco na Guerra ao Terror fez com que as relações e diálogos entre Cuba e os Estados Unidos diminuíssem até quase um "silêncio" político durante as duas administrações do presidente Republicano. Do início de seu mandato até quase o fim, as relações com Cuba não sofreram nenhuma alteração significativa: o embargo comercial continuou e as medidas restritivas que Bush adotou para Cuba apenas o reforçaram. Portanto, a política de isolamento e sufocamento da economia cubana se manteve e foi aumentada pelas restrições do governo Bush. 


\section{Raúl Casto e Barack Obama}

Em agosto de 2006, por motivos de saúde, Fidel Castro se afastou temporariamente do cargo de liderança de Cuba, transferindo suas funções e capacidades para seu irmão Raúl Castro como uma medida provisória. Era a primeira vez que o mandante cubano saía de seu cargo desde a Revolução em 1959. Até 2008, Fidel Castro sempre apoiou o governo do irmão, até que nesse ele oficializou sua saída do poder e, assim, efetivou a posse de Raúl Castro (MORRONE, 2008).

O processo decisório que marcou o embargo comercial a Cuba por quase 40 anos e as organizações e comitês montados ao longo do tempo, todas em virtude de promover uma transição pacífica para um modelo democrático de governo, foram a forma que os Estados Unidos travaram uma "guerra política silenciosa" contra o regime de Fidel Castro desde a Revolução em 1959, esperando que, de alguma forma, a fragilidade da economia cubana acarretasse seu colapso. Mas ao longo dos anos houve pelo menos três momentos nos quais o governo estadunidense vislumbrou o fim do regime da Revolução: na invasão da Baía dos Porcos; no fim da União Soviética e no momento da transição de poder para Raúl. O irmão de Fidel Castro era percebido como mais moderado, causando com que se reavivasse a atenção de diversos atores nos Estados Unidos, na expectativa de mudanças no cenário político da ilha.

O período político que se iniciava em Cuba sob o mandato de Raúl Castro, apesar de pautado nos fundamentos da mesma política de Fidel Castro, trouxe uma série de mudanças sutis e gradativas na Ilha, rumo a uma modernização da economia. Embora organizações como a CANF não reconhecessem a legitimidade do novo governante, começaram a surgir debates na comunidade cubano-americana e no governo dos Estados Unidos acerca da real possibilidade de uma transição política em Cuba e o papel do país e dos cubano-americanos nesse processo. (MESA-LAGO; PÉREZ-LOPES, 2013) ${ }^{18}$.

Simultaneamente, no mesmo ano em que Raúl Castro assumiu o poder oficialmente, Barack Obama vencia as eleições presidenciais pelo partido Democrata. No que tange à Cuba, assim como a administração de Clinton, Obama adotou uma postura de flexibilização das relações com a ilha para permitir uma reaproximação entre os países. Ainda assim, como todos os presidentes até então, Obama reforçou a condicional retirada do embargo a uma transição para a democracia em Cuba. Como candidato, Obama discursou na sede da CANF no distrito de Miami - Dade, para o público cubano-americano. Ele criticou a política do governo Bush para Cuba, alegando que os 8 anos de silêncio diplomático e as restrições adicionais impostas não ajudaram na transição democrática da ilha. Para sua estratégia de governo ele indicou suas intenções de retirar as restrições de viagens de visitas familiares para Cuba e aumentar a quantidade de remessas de dinheiro permitidas, sempre colocando que isso não significava um relaxamento total das relações com a ilha, mas 
sim uma aproximação para o diálogo. Entretanto, na ocasião, Obama assinalou que as relações diplomáticas poderiam ser a solução para as tensões entre os dois países.

Os autores Mesa-Lago e Peréz-Lopes (2013) ao compararem todos os Presidentes dos Estados Unidos que lidaram com Cuba desde 1959 observam pertinentemente que desde 1961 houve momentos de endurecimento e relaxamento das restrições econômicas impostas pelo governo Federal e pelo embargo econômico, condicionados pelo tipo de governo de cada Presidente. As épocas de maior relaxamento e maior flexibilidade foram as de governos Democratas no poder - Jimmy Carter, Bill Clinton e Barack Obama -, e as épocas de endurecimento foram as de governos Republicanos - Richard Nixon, Ronald Reagan e George W. Bush (MESA-LAGO; PERÉZ-LOPES, 2013, p.7).

A manutenção do embargo econômico se mostrou como uma preferência política de todos os Presidentes até 2014, apesar de que, nos períodos de governos Democratas, houve sinais de vontade de reaproximação política com Cuba como solução diplomática para se alcançar a normalização das relações. Com o decorrer do tempo, essa política ficou tão arraigada que deixou de ser uma estratégia do Executivo e passou a ser uma Lei, diluindo a possibilidade de muda-la. Também é possível notar a preocupação dos candidatos à Presidência (durante e perto de épocas eleitorais) com o alinhamento de sua política com os interesses da comunidade cubano-americana, especialmente no que tange à política externa para Cuba, visto a importância dos mesmos como eleitores. Nos fenômenos descritos e analisados, fica clara a atenção específica com os cubano-americanos da Flórida, diante do peso do colégio eleitoral do Estado.

\section{A Normalização de $2014^{19}$}

No dia 14 de dezembro de 2014, o Presidente Obama fez um anúncio histórico para a política externa dos Estados Unidos para Cuba. Em discurso oficial e ao vivo, disse que a velha estratégia de isolamento de Cuba estava obsoleta e falhou em cumprir seu objetivo e promover uma transição democrática na Ilha. Além disso, segundo Obama, a política de isolamento terminava por apenas prejudicar a sociedade cubana, em vez de minar a capacidade do governo da Revolução de se sustentar. A nova estratégia anunciada apostava na normalização de relações como meio de promover mudanças endógenas em Cuba. Após mais de cinquenta anos, Cuba e os Estados Unidos reestabeleceriam relações diplomáticas através de um processo de normalização gradual ao longo do resto de sua gestão, começando pela abertura de embaixadas em ambos países.

A estratégia apresentada por Obama apostava em que a inserção de Cuba no mundo moderno faria com que a sociedade cubana saísse do isolamento informacional e se transformasse, levando a um rumo natural de transformações do governo de Cuba. Se tratava de uma ação com resultados de longo prazo, 
visando a transformação do regime governamental de Cuba de forma "natural". Para atingir a normalização, Obama flexibilizaria o máximo de políticas que competiam ao Executivo, porém o embargo econômico, o maior obstáculo para uma normalização total, estava fora de seu alcance, cabendo ao Congresso a decisão final.

O processo de normalização promovido pela administração Obama foi feito de forma unilateral e secreta pelo Executivo. Por meio de negociações sigilosas entre comitês dos braços Executivos de Cuba e Estados Unidos, com o Vaticano como mediador, ambos os governos chegaram a um consenso e no mesmo dia do anúncio de Obama, Raúl Castro também anunciou a retomada de relações diplomáticas com os Estados Unidos.

Apesar de ter tido um significado importantíssimo para a história dos dois países, a normalização foi incompleta. A unilateralidade do Executivo dos Estados Unidos causou furor na esfera legislativa, visto que a maior parte dos Republicanos e até alguns Democratas eram contra uma normalização com Cuba. A rejeição a um processo de normalização ficou ainda mais evidente entre congressistas cubano-americanos, como Marco Rubio (senador republicano pela Flórida), Bob Menendez (senador democrata por Nova Jersey) e Mario Días-Balart (deputado republicano pela Flórida). Essa mesma rejeição também se manifestou entre os setores mais conservadores da comunidade cubano-americana. Porém, a opinião pública geral e até a comunidade cubanoamericana se mostrou mais favorável à normalização do que era esperado pela própria administração de Obama.

$\mathrm{O}$ resultado da oposição da classe política à nova estratégia para Cuba foi que o Congresso não fez uma revisão efetiva do embargo econômico, mantendo a Lei Helms-Burton em vigor. Contudo, isto não impediu que o processo de normalização fosse levado adiante por Obama utilizando o máximo das capacidades que competiam ao Poder Executivo. A normalização começou com a troca de prisioneiros políticos de ambos os países e, durante o ano seguinte, foram reabertas as embaixadas dos Estados Unidos em Havana e a de Cuba em Washington. No decorrer de 2015 e 2016, a administração Obama foi liberando uma série de pacotes de medidas de flexibilização para Cuba. Essas medidas reestabeleceram as viagens aéreas e marítimas de transporte de passageiros entre os dois países, autorizaram o turismo de estadunidenses para Cuba, permitiram algum grau de investimento econômico em áreas chave da economia e infraestrutura de Cuba, mais especificamente nas telecomunicações e, finalmente, a Ilha foi removida da lista de países que patrocinam o terrorismo na qual havia sido incluída na Guerra Fria (vale apontar que Obama também iniciou um processo de desativação da base de Guantánamo como prisão). Além disso, outros dois movimentos foram simbolicamente importantes para a estratégia de normalização no âmbito internacional. O primeiro deles foi a abstenção dos Estados Unidos nas Nações Unidas sobre uma resolução a favor 
do embargo contra Cuba, quebrando a tradição de ser praticamente o único voto a favor nos últimos 24 anos. O segundo foi o parecer favorável ao retorno de Cuba à Organização dos Estados Americanos (OEA), da qual os Estados Unidos pressionaram e obtiveram a expulsão da Ilha na década de 1960.

No que diz respeito às relações bilaterais entre Cuba e Estados Unidos, o processo de normalização também incluiu uma visita histórica de Obama à ilha de Cuba. Foi a primeira vez que um presidente estadunidense pisou em Cuba desde 1928. A visita incluiu negociações a portas fechadas com Raúl Castro e uma coletiva de imprensa conjunta com o mandatário cubano acerca do processo de normalização. Contudo, uma possível visita de Obama a Fidel Castro não ocorreu e o ex-comandante cubano veio a falecer no final de 2016.

A morte de Fidel Castro também teve seu papel no processo de normalização, visto que Raúl Castro teria anunciado a sua saída do governo em 2018. Em teoria, a ausência dos irmãos Castro no governo de Cuba seria um argumento a favor do processo de normalização, uma vez que a oposição política e social tinha em sua retórica a manutenção de uma estratégia de isolamento como forma de derrubar o regime castrista, incluindo cláusulas proibitivas da participação dos irmãos Castros em um processo de redemocratização do governo de Cuba, que levaria à auto-extinção da Lei Helms-Burton. Coincidentemente, Fidel Castro morreu semanas depois da eleição de 2016, que teve o candidato republicano Donald Trump como vitorioso, em cuja campanha eleitoral foi mencionada brevemente a possibilidade de retroceder com o processo de normalização, apelando ao público a favor da velha retórica anticastrista e estratégia da política austera.

Após as eleições, Obama ainda deu continuidade ao processo de normalização até as vésperas do final de seu mandato, em 20 de janeiro de 2017, extinguindo a política migratória Wet Feet/Dry Feet criada na década de 1990 pelo governo Clinton. O argumento de Obama seria de que a antiga política fora criada dentro de um contexto de antagonismo entre os dois países, no qual os cubanos imigrados eram tratados como refugiados políticos, o que justificava o tratamento privilegiado a eles quando imigravam ilegalmente para os Estados Unidos. Em um processo de normalização, este não era mais o caso, então teoricamente as relações migratórias deveriam ser normalizadas também. Apesar da extinção da política Wet Feet/Dry Feet, a Lei do Cuban Adjustment Act permaneceu, visto que a mesma não necessariamente se aplica a cubanos imigrantes ilegais e que ela está respaldada na existência da Lei Helms-Burton, impedindo o poder Executivo de revoga-la.

A extinção do Wet Feet/Dry Feet não apenas foi uma mudança importante nas relações migratórias entre Estados Unidos e Cuba, como também acabou servindo como um meio para solidificar o processo de normalização, considerando que o Republicano Donald Trump, que tomaria posse em poucos dias, vinha de uma campanha eleitoral pautada por um forte discurso contra a 
imigração ilegal e críticas ao governo de Clinton (já que sua candidata opositora, Hillary Clinton, foi primeira-dama durante o governo de Bill Clinton), fazendo com que retroceder na extinção da Wet Feet/Dry Feet fosse contraditório com seu discurso eleitoral.

As medidas feitas por Obama atenderam ao objetivo de promover a transformação cultural em Cuba, mas também tiveram seu impacto nos Estados Unidos. $\mathrm{O}$ acesso à internet pela sociedade cubana, embora ainda embrionário, obteve grandes avanços, conectando a Ilha mais diretamente com o resto do mundo. A sociedade estadunidense começou a enxergar de forma mais positiva a criação de laços com os cubanos, desmistificando um pouco o tabu do país comunista inimigo isolado, herança da Guerra Fria, e da manutenção de um paradigma político de austeridade e isolacionismo.

É importante ressaltar que, mesmo promovendo pequenas flexibilizações para Cuba e seus primeiros anos, a administração Obama esperou até 2014 para iniciar o processo de normalização, isto é, Obama já havia sido reeleito e não tinha possibilidade concorrer de novo. Não ter a reeleição como uma meta futura diminuiu consideravelmente o custo político de uma medida tão radical, favoreceu a imagem dos Estados Unidos perante os outros países das Américas (visto que o país estava isolado em sua posição austera contra Cuba) e deixou um legado pessoal histórico para Obama. Em um balanço geral, o contexto de aproximação que se desenrolou durante o governo de Obama pode ser bem ilustrado pela expressão no título do livro de Francisco López Segrera (2017), "The United States and Cuba: From Closest Enemies to Distant Friends" (Os Estados Unidos e Cuba: De Inimigos próximos a Amigos Distantes) ${ }^{20}$. A reaproximação em si foi uma quebra do velho paradigma da política austera e do isolacionismo que surgiu logo no pós-Revolução. Ao longo dos anos, diversos atores alternaram seu nível de importância e influência na política externa estadunidense para Cuba, solidificando, até legislativamente, uma linha contínua de estratégia para a Ilha. É possível argumentar que a estratégia política norte-americana de austeridade foi se descentralizando em seu processo decisório e se tornando cada vez mais enraizada na esfera governamental, o que ajudou na perpetuidade do paradigma de "Closest Enemies". O término da Guerra Fria e a continuidade da estratégia antiga enrobustece o argumento de que tanto a complexidade decisória acerca do tema, quanto a manutenção do governo Castro acabaram resultando em uma estagnação da política externa para Cuba.

Com a saída de Fidel do poder e a chegada de Obama à presidência dos Estados Unidos, a nova administração estadunidense esperou o segundo mandato para apostar na mudança de forças e interesses internos, em ambos os países, de tal forma para que fosse possível custear a quebra do antigo paradigma e a adoção de uma nova estratégia. Além disso, o governo de Obama se utilizou da reaproximação com Cuba para buscar uma melhoria da 
imagem dos Estados Unidos perante outros países da América Latina. Apesar de não ter alcançado a normalização total, o governo de Obama deu início a uma lenta caminhada rumo a uma era diferente nas relações dos Estados Unidos com Cuba.

\section{Notas}

1 Mestre em Relações Internacionais pela PUC-MG, doutorando pelo Programa de PósGraduação em Relações Internacionais San Tiago Dantas (UNESP, UNICAMP e PUC-SP) e pesquisador do Instituto Nacional de Ciência e Tecnologia em Estudos sobre Estados Unidos (INCT-INEU) e do Instituto de Estudos Econômicos e Internacionais da UNESP (IEEI-UNESP). Atualmente é Visiting Scholar na University of South Florida, trabalhando no Institute for the Study of Latin America and the Caribbean (ISLAC). E-mail: ajguevaramartinez@ gmail.com

2 HOLDEN Robert H., ZOLOV. Eric. Latin America and the United States: a documentary history. New York : Oxford University, 2000. SCHOULTZ, Lars. Estados Unidos: poder e submissão: uma história da política norte - americana em relação a América Latina. Tradução Raul Fiker ; revisão técnica Mary Anne Junqueira. EDUSC, Bauru :2000. GRANDIN, Greg. Empire's workshop: Latin America, the United States, and the rise of the new imperialism Henry Holt, New York: 2007. PREVOST, Gary. Cuba. In: Vanden, Harry. E; Prevost, Gary. Politics of Latin America: the power game. Oxford ; New York: Oxford University Press, 2015.

3 GUEVARA, Alfredo J. M. O Processo Decisório do Cuban Adjustment Act: Variações de contexto e manutenção da lei (1966 a 2014): PUC-Minas (Pontíficia Universidade Católica de Minais Gerais). 2015. Dissertação (Mestrado) - Programa de Pós Graduação em Relações Internacionais PUC-Minas

4 SUCHLIKI, Jaime. Cuba: From Columbus to Castro and Beyond. Brassey's Inc: Washington, D.C.: 2002. BOSCH, Juan. De Cristóbal Colón a Fidel Castro: el Caribe, frontera imperial. Publisher: Miguel Angel Porrua: 2009.

5 LEOGRANDE, William M. and KORNBLUH, Peter. 2015. Back Channel to Cuba: The hidden history of negotiations between Washington and Havana. Chapel Hill: The University of South Carolina Press.

6 MORRONE, Priscila. A Fundação Nacional Cubano-Americana (FNCA) na Politica Externa dos Estados Unidos para Cuba: UNESP (Universidade Estadual Paulista "Júlio de Mesquita Filho), UNICAMP (Universidade de Campinas) e PUC-SP (Pontifícia Universidade Católica de São Paulo). 2008. Dissertação (Mestrado) - Programa de Pós-Graduação em Relações Internacionais "San Tiago Dantas”. Disponível em: $<$ http://www.dominiopublico.gov.br/download/texto/cp061066.pdf> Acesso em 06/09/2013. SCHOULTZ, Lars. That infernal little Cuban republic : the United States and the Cuban Revolution. Chapel Hill: University of North Carolina Press, 2009.

7 ALISSON, T. Graham and Zelikow Philip. The Essence of Decision: Explaining the Cuban Missile Crisis. New York: Longman. 1999

8 GOTT, Richard. Cuba. Uma Nova História. Rio de Janeiro: Jorge Zahar Editora, 2006. DÍAZ, Antonio, A., La emigración cubana hacia Estados Unidos a la luz de su política inmigratoria. CEMI, Centro de Estudios de Migraciones Internacionales. La Habana, Cuba, 2000. 
9 FERNANDÉZ, Consuelo M; QUIJANO, Magali M. ¿Circuito Cerrado? Reflexiones sobre los determinantes en las salidas ilegales del país. CEMI, Centro de Estudios de Migraciones Internacionales, La Habana, Cuba. 2003. Disponível em: < $\underline{\text { http://biblioteca.clacso.edu.ar/ar/ }}$ libros/cuba/cemi/circuito.pdf $>$. Acesso: 02/01/2013.

10 CHÁVEZ, Ernesto R., A crise migratória do verão de 1994. Balanço e perspectivas do fluxo emigratório cubano: 1984-1996, Revista Brasileira de Estudos Populacionais, Campinas, 13(2). 1996. Disponível em: <http://www.abep.nepo.unicamp.br/docs/rev_inf/ vol13 n2 1996/vol13 n2 1994 2artigo 135 167.pdf > Acesso: 27 dez. 2012. GOBIERNO DE CÜBA. Acuerdos migratorios Cuba-EEUU. 2015. Disponível em: $<$ http://www.cubagob. cu/rel_ext/acuerdos.htm> Acesso em: 23 de janeiro de 2015 .

11 LAMRANI, Salim. El Lobby Cubano em Estados Unidos de 1959 Hasta Nuestros Días, 2003. Disponível em: <www.rebelion.org/libros/lobby_cubano.pdf> . Acesso em: 23/02/2014

12 PECEQUILO, Cristina Soreanu. A Política Externa dos Estados Unidos: continuidade ou mudança? Porto Alegre: Editora da UFRGS, 2005

13 CARCANHOLO, Marcelo, D.; NAKATANI, Paulo. Crise e Reformas de Mercado: A Experiência de Cuba nos Anos 90, Problemas del Desarrollo, Revista Latinoamericana de Economía, v. 33, 128, México:IIEc-UNAM, 2002. Disponível em: http://www.ejournal. unam.mx/pde/pde128/PDE12807.pdf. Acesso: 02 mar. 2017.

14 ALZUGARAY, Carlos. De Bush a Bush: balance y perspectivas de la politica externa de los Estados Unidos hacia Cuba y el Gran Caribe, América Latina y el (des)orden global neoliberal. Hegemonía, contrahegemonía, perspectivas. Buenos Aires: Editora CLACSO, Consejo Latinoamericano de Ciencias Sociales, 2004.

15 GUTIÉRREZ, Carlos, G. Los latinos y la política exterior de Estados Unidos. Foreign Affairs en Español, p. 113-122, otoño- invierno, 2002.

16 MARRAWI, José B.; MÉNDEZ, José L. M. La República de Miami. La Habana: Editorial de Ciencias Sociales, 2005.

17 AYERBE, Luis F. A Revolução Cubana. São Paulo: Editora da UNESP, 2004;

18 MESA-LAGO, Carmelo; PÉREZ-LÓPEZ, Jorge. Cuba Under Raúl Castro: Acessing the Reforms, Boulder CO: Lynn Rienner, 2013.

19 Considerando que o fenômeno da normalização é recente, a maior parte das análises feitas na sessão do artigo que trata da normalização é resultado da produção jornalística e científica do autor, incluindo artigos de jornal no acompanhamento de todo o processo e entrevistas a fontes primárias sobre o caso, que vem sendo desenvolvidas para elaboração de tese doutoral sobre o tema.

20 SEGRERA, Francisco, L. The United States and Cuba: From Closest Enemies to Distant Friends. Maryland, Lanham: Rowman and Little Field, 2017.

Recebido em 06/04/2017

Aprovado em 22/09/2017 